\title{
Attitudes of Indonesian Medical Doctors and Medical Students Toward Genome Editing
}

\author{
Safira Nur Izzah' \\ Dimas Setyanto' \\ Nurina Hasanatuludhhiyah ${ }^{2,3}$ \\ Danti Nur Indiastuti ${ }^{2,3}$ \\ Zamal Nasution ${ }^{4}$ \\ Annette d'Arqom ${ }^{2,3}$ \\ 'Faculty of Medicine, Universitas \\ Airlangga, Surabaya, Indonesia; ${ }^{2}$ Division \\ of Pharmacology and Therapy, \\ Department of Anatomy, Histology, and \\ Pharmacology, Faculty of Medicine, \\ Universitas Airlangga, Surabaya, \\ Indonesia; ${ }^{3}$ Airlangga Research Group for \\ Translational Medicine and Therapeutic, \\ Universitas Airlangga, Surabaya, \\ Indonesia; ${ }^{4}$ Institute for Population and \\ Social Research, Mahidol University, \\ Bangkok, Thailand
}

Correspondence: Annette d'Arqom Division of Pharmacology and Therapy, Department of Anatomy, Histology, and Pharmacology, Faculty of Medicine, Universitas Airlangga, Jl. Mayjen Prof. Dr. Moestopo 47, Surabaya, 6013I, Jl. Mayjen Prof. Dr. Moestopo 47, Indonesia Email annette-d-a@fk.unair.ac.id
Purpose: This study aimed to measure the attitudes of Indonesian medical doctors and students toward new technology in genome editing.

Materials and Methods: Online questionnaires regarding attitudes toward genome editing on health and non-health conditions, both in somatic cells and embryo, were distributed through researcher networks, email and social media specific to medical doctors and students. The data of 1055 valid questionnaires were processed; descriptive and association analyses between sociodemographic factors and attitudes toward genome editing were performed. Email in-depth interview was performed to explore the respondents' answers.

Results: The results showed that Indonesian medical doctors' and students' knowledge of genome editing was limited and correlated with gender, place of residence, religion, education, marital status, childbearing and experience abroad. More than half of respondents supported genome editing for the treatment of fatal and debilitating diseases both in somatic cells and embryos, implying their consent to edited gene inheritance. However, this approval decreased when applied to non-health-related aspects, such as physical appearance, intelligence and strength. Factors affecting their attitudes toward genome editing included their status as medical doctors or students, gender, age, education, religion, economic status and place of residence.

Conclusion: Increasing knowledge and awareness of Indonesian medical doctors and students regarding genome editing is important. Even though its application in health-related matter was supported by a majority of the respondents, discussion from ethical and religious perspectives is necessary to ensure the acceptance.

Keywords: developing country, CRISPR/Cas, good health and well-being

\section{Introduction}

DNA mutations are a major contributor to the development of diseases. Research into targeted therapies, as part of precision or personalized medicine, continues to expand and to include more mutations causing diseases. ${ }^{1}$ Two strategies for targeted therapy involving genetic mutation are gene therapy and genome editing, which have been applied to several diseases. In principle, gene therapy works by introducing DNA/RNA into the cells, removing or changing defective genes to drive the correct protein production. Genome editing in particular, which is one of the gene therapy techniques, is to remove, to disrupt or to correct faulty elements of DNA within the gene and leads to change sequence of the gene. ${ }^{2} \mathrm{Up}$ to now, the approved gene therapies do not alter the genomic sequences, for instance Zynteglo ${ }^{\circledR}$ for $\beta$-thalassemia, ${ }^{3}$ Luxturna $^{\circledR}$ for Leber congenital amaurosis or retinitis pigmentosa ${ }^{4}$ and Zolgensma $^{\circledR}$ for spinal 
muscular atrophy, ${ }^{5}$ whilst the genome editing approach is still under clinical trials such as for lung cancer ${ }^{6}$ and blood disorder. $^{7}$

Genome editing has become a rising star since the investigation of CRISPR/Cas9 found a defensive system from phage in bacteria., ${ }^{8,9}$ Currently, editing diseases caused by mutations and introducing the correct donor template have become much simpler and more affordable. Several components are required for CRISPR/Cas9 gene editing, including a gRNA designed to target a particular PAM sequence, the Cas9 enzyme to cut DNA and potentially a donor template. ${ }^{10}$ CRISPR/Cas9 recognizes a specific sequence, creates a double-strand break on the DNA and the cell automatically performs DNA repair, constituting an effective tool for genome editing.

CRISPR/Cas9 has been widely used for its simplicity and affordability. ${ }^{11}$ In fact, in 2020, CRISPR/Cas9 technology was awarded the Nobel Prize for its broad possible applications, simple handling and affordable price. However, low efficiency and off-targeting remain a concern in its application. ${ }^{10,12,13}$ Since the discovery of CRISPR/Cas9, many studies have been performed in vitro in human cells and in vivo in a range of animal models to correct disease-caused mutations and to create mutations for gene inactivation. ${ }^{13,14}$ Mostly, this powerful method has been applied to somatic cells, but concerns have been expressed by scientists regarding its application to germline cells that allows inheritance of the edited gene. ${ }^{15}$ Unfortunately, a red alert was raised in 2018 when one group of Chinese scientists announced the birth of twin babies for whom the CCR5 gene had been edited. Inactivation of this gene made the babies resistant to HIV invasion. ${ }^{16,17}$ Moreover, ethical concerns has been raised on the application of this technology to enhance human ability such as memory or intelligence. ${ }^{18}$

Despite the controversies, medical doctors and students need to understand the latest technology, which could potentially affect their future practice since this technology rapidly develops toward its clinical application. ${ }^{19}$ Acceptance and attitude of general public, medical doctors and students on gene therapy and genome editing have been extensively investigated and reviewed, with acceptance of this technology being affected by the education, religion, gender, age, economic status and trust to the scientist and government. $^{20}$ Respondents with medical background are more likely to accept genome editing than are the general public. ${ }^{21}$ Moreover, due to the CCR5 babies scandal, public awareness of genome editing technology application, risk, safety and ethical problems increased, while the acceptance of this technology reduced. ${ }^{22}$ In Indonesia, genome editing is not part of a focus in Indonesian medical education, ${ }^{23}$ and as it is a country with a big religious population, the controversy regarding the ethics of some health approaches is unavoidable. $^{24}$ Therefore, we conducted this study to explore the attitudes of Indonesian medical doctors and students toward human genome editing and the sociodemographic factors that might affect their attitude.

\section{Materials and Methods Study Design and Data Collection}

This cross-sectional study was part of a gene therapy and genome editing study in Indonesia which was conducted from May to December 2020, and ethics approval was obtained from the Faculty of Medicine, Universitas Airlangga No. 156/EC/KEPK/FKUA/2020. Before the start of the questionnaire, a page explaining the aim and content of the survey was provided, and informed consent, including for publication of anonymized responses, was obtained if the respondent clicked the BEGIN button to start the survey.

Primary data were collected from online questionnaires distributed through the researcher's network, email and social media of medical doctors and students. Research staff shared and guided the respondents to access the online questionnaire, and the respondents completed and submitted the questionnaires independently. Respondents of this study comprised only Indonesian medical doctors and medical students, over 18 years of age, that were Indonesian citizens and who had studied in a medical program or graduated from an Indonesian Medical Faculty. Fifteen respondents were then contacted based on their answers to the online questionnaire; among these, only 10 respondents replied, and an in-depth email interview was performed by SNI, DS and Ad'A. ${ }^{25}$

\section{Survey Instrument}

The attitudes of respondents to genome editing were measured using a set of questionnaires. The questionnaire consisted of two sections, which comprised basic information of respondents and questions regarding their attitudes on genome editing. The questionnaire was adapted and translated by two native Indonesians from "A Global Social Media Survey of Attitudes to Human Genome Editing". ${ }^{26}$ The translated questionnaire was further piloted among 20 Indonesian medical doctors to ensure 
the understanding of the respondents. The survey was divided into seven sections: (1) respondent's characteristics (gender, age, place of residence, marital status, childbearing, education, work experience, religion and experience abroad); (2) general attitudes toward genome editing; (3) attitudes toward genome editing in somatic cells for fatal and debilitating diseases; (4) attitudes toward genome editing in embryos for fatal and debilitating diseases; (5) attitudes toward genome editing in the embryo to change individual characteristics, such as physical, intelligence quotient (IQ) and strength; (6) factors affecting the attitudes toward genome editing; and (7) their agreement in genome editing implementation in Indonesia. Finally, respondents were asked to answer an open-ended question regarding their concerns toward genome editing. The in-depth interview questions were developed based on each respondent's answer, focusing on their concerns on genome editing.

\section{Analytical Procedure}

Respondents were divided into two groups: doctors and students. The religion, place of residence and economic status were simplified into two categories each, ie, majority and minority; inside or outside the main islands; and lower and higher economic status, respectively. The attitudes toward genome editing in somatic cells and in embryos as well as its application in Indonesia were measured using a 5-point Likert scale, rated from "strongly disagree" to "strongly agree", which was aggregated to "disagree", "neutral" and "agree", while attitudes toward genome editing in embryos to change individual characteristics were measured using yes/no answers. Additionally, participants chose from a list the factors that affected their attitudes toward genome editing, and the number of respondents per factor was calculated and divided by the total respondents; respondents could also write in their concerns regarding genome editing technology.

Data were processed using Microsoft Excel and analyzed using SPSS 25.0 (IBM, Chicago, IL, USA), and graphs were visualized using GraphPad Prism version 5.00 (La Jolla, California, USA). Descriptive statistical analyses were performed, and response rates were calculated as percentages on every item related to categorical variables. Differences between groups were measured using the t-test or Mann-Whitney $U$ and Kruskal-Wallis $H$-test to determine the sociodemographic factors influencing the respondents' attitudes toward genome editing; significance was defined as a $p$-value $<0.05$. The effect size further performed to measure the strength of the differences between two groups, with the interpretations for effect size $g$ being: $g=0.20$ as small, $g=0.5$ as medium and $g=0.8$ as large, following the criteria proposed by Hedges (1985). ${ }^{27,28}$

\section{Results}

\section{Characteristics of Respondents}

Of the 1076 responses received, 1055 questionnaires were valid and used in the final analysis, corresponding to an effective rate of $98.05 \%$. Four returned responses were excluded because they were incomplete, and 17 responses were excluded due to unmet the eligibility criteria. The ratio between doctors and students was almost 1:1, with females as the majority. A discrepancy of age was observed between the two groups: all the respondents in the student group were between 18 and 30 years old, while young doctors (18 to 40 years old) were the majority in the medical doctor group. As expected, the majority of respondents were located in Java and Bali, which are the most developed provinces in Indonesia and have more doctors and medical schools compared with other provinces. Moreover, as Indonesia is a Muslim majority country, two-thirds of the respondents in each group were Muslim. Based on their selfproclaimed economic status, the majority of respondents in the two groups had lower economic status. As expected, the education between the two groups differed; only $35.8 \%$ of the medical doctors pursued specialization/post-graduate studies. However, no significant difference was found between doctor and student respondents participating in mobility programs in other countries $(20 \%$ vs $15.9 \%$, respectively). The difference between the two groups also could be observed concerning their work experience. The majority of doctors had more than 5 years of working in their field, while the majority of students still studied in their fifth year. Nearly all respondents in the student group were unmarried and without children, while two-thirds of respondents in the doctor group were married and with children. Characteristics of the respondents are summarized in Table 1.

\section{Attitudes Toward Genome Editing}

Fifteen questions assessed attitudes toward genome editing applications in humans (Table S1). The results showed very low familiarity with genome editing in the doctor and student groups (12.2\% and $13.1 \%$, respectively) even 
Table I Characteristics of Respondents

\begin{tabular}{|c|c|c|c|c|}
\hline Characteristics & Medical Doctors $(N=534), N$ [\%] & Medical Students $(N=52 I), N$ [\%] & $x^{2}$ & $\boldsymbol{p}$ \\
\hline Sex & & & 3.29 & 0.07 \\
\hline Male & $190[35.6]$ & I58 [30.3] & & \\
\hline Female & $344[64.4]$ & $363[69.7]$ & & \\
\hline \multicolumn{5}{|l|}{ Age } \\
\hline $18-30 y$ & $235[44.0]$ & $521[100]$ & 407.1 & 0.000 \\
\hline $30-40$ y & $198[37.1]$ & & & \\
\hline $40-50$ y & $72[13.5]$ & & & \\
\hline$>50 y$ & $29[5.4]$ & & & \\
\hline Place of Residence & & & 0.52 & 0.47 \\
\hline Java and Bali Islands (main islands) & $311[58.2]$ & $292[56.0]$ & & \\
\hline Other Islands & $223[4 \mid .8]$ & $229[44.0]$ & & \\
\hline Religion & & & 14.14 & 0.000 \\
\hline Majority & $375[70.2]$ & $418[80.2]$ & & \\
\hline Minority & 159 [29.8] & $103[19.8]$ & & \\
\hline Education & & & 1055.0 & 0.000 \\
\hline High School & & $392[75.2]$ & & \\
\hline Bachelor Degree & & $129[24.8]$ & & \\
\hline MD Degree & 343 [64.2] & & & \\
\hline Specialization/Post-grad & $191[35.8]$ & & & \\
\hline Marital Status & & & 441.3 & 0.000 \\
\hline Not Married & $205[38.4]$ & $5 \mid 4$ [98.7] & & \\
\hline Married & $329[6 \mid .6]$ & $7[1.3]$ & & \\
\hline Childbearing & & & 368.54 & 0.000 \\
\hline No & $250[46.8]$ & 518 [99.4] & & \\
\hline Yes & $284[53.2]$ & $3[0.6]$ & & \\
\hline Experience & & & 89.65 & 0.000 \\
\hline$\leq 5$ years & $198[37.1]$ & $345[66.2]$ & & \\
\hline$>5$ years & $336[62.9]$ & 176 [33.8] & & \\
\hline Economic Status & & & 8.04 & 0.005 \\
\hline Lower & $373[69.9]$ & $404[77.5]$ & & \\
\hline Higher & $161[30.1]$ & 117 [22.5] & & \\
\hline Experience Abroad & & & 3.01 & 0.083 \\
\hline No & $427[80.0]$ & $438[84.1]$ & & \\
\hline Yes & $107[20.0]$ & $83[15.9]$ & & \\
\hline
\end{tabular}

Note: Boldface $p$-values indicate significant differences between groups.

though more of the respondents had heard of this technology $(21.3 \%$ and $28 \%$, respectively, Figure 1A). The respondents were more familiar with genetically modified food $(27.1 \%$ and $20.4 \%$, respectively) or at least had heard of this issue (38.8\% and $28.2 \%$, respectively, Figure 1B). Despite genome editing technology being in the spotlight in these past 3 years with the CCR 5 edited babies scandal and Nobel Prize winners, the respondents' knowledge was significantly lower compared with GMO and the more common issues in gene technology which have attracted more media coverage $(p<0.01)$. This was an unexpected finding, because medical doctors' and students' knowledge on this technology was lower than the US public's knowledge $(31 \%){ }^{29}$

Although respondents had little knowledge of this field, no specialty terms were used in the questionnaire, allowing them to complete the survey. The majority of respondents $(60.76 \%)$ supported the application of 

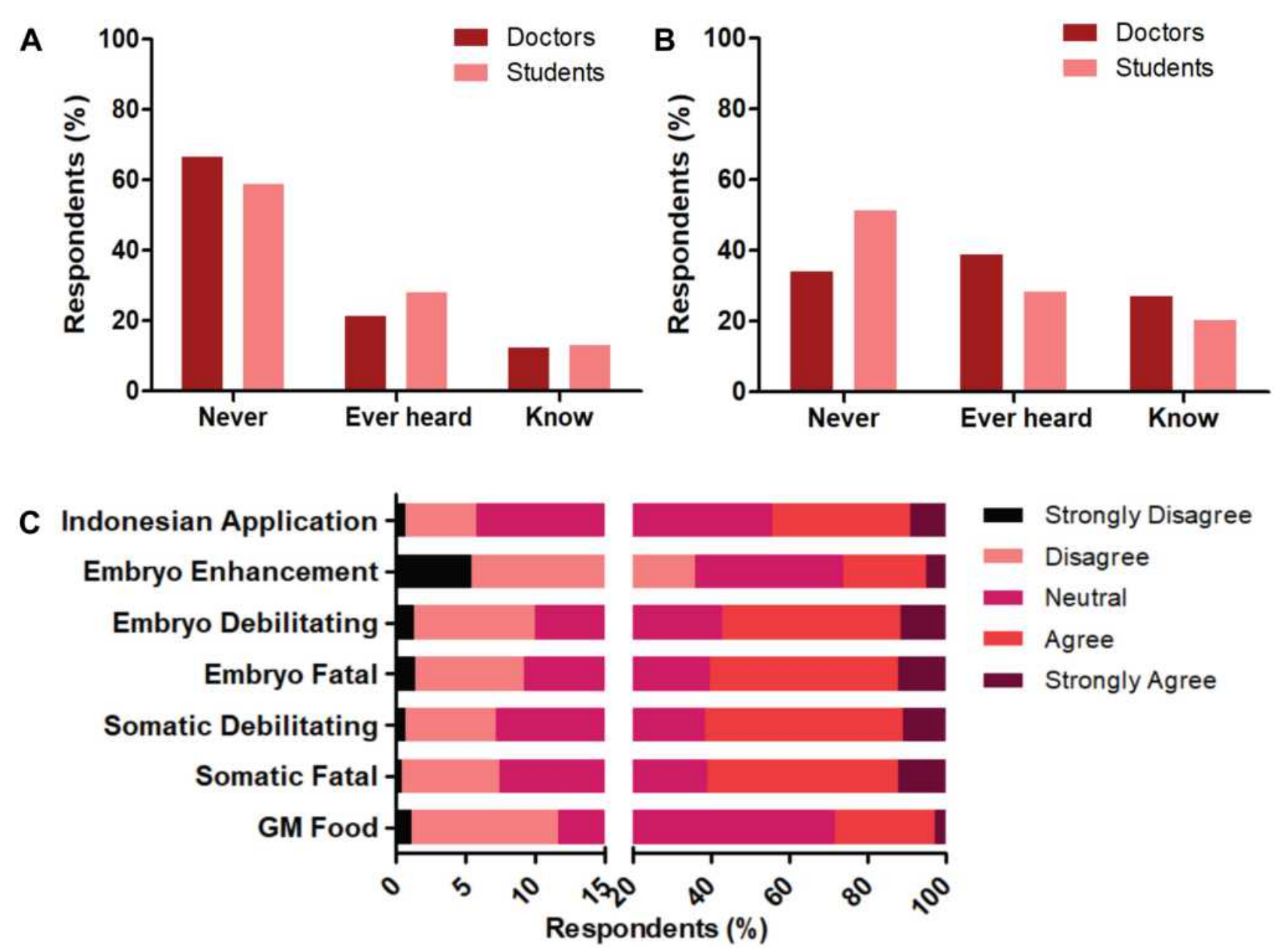

Figure I Knowledges and attitudes of Indonesian medical doctors and medical students toward genome editing. (A) Knowledge on genome editing . (B) Knowledge on genetically modified food. The knowledge was divided into "never heard", "ever heard but not familiar" and "know" which means the respondents were familiar with the technology including superficial knowledge to deep knowledge. (C) Attitudes of all respondents on GM food and genome editing application in health and non-healthrelated matter, including application in Indonesia.

genome editing as therapy for fatal diseases in somatic cells, which prohibits inheritance in the next generation. Regarding its application in alleviating the burden of debilitating diseases in somatic cells, an almost similar number was obtained: $61.33 \%$ supported this aim. The respondents in the doctor group were more likely to support the applications in somatic cells for fatal and debilitating diseases compared to the student group ( $p=0.000$ and $p=0.000$, respectively). Meanwhile, the support for the application of this technology in the embryo stage was not significantly different between the two groups (Table 2). However, the values of effect size $g$ were 0.22 for both questions or had small effect, although the results were statistically significant.
Overall, the number of respondents who agreed was slightly reduced when the application was to embryos, meaning the edited gene could be inherited by the next generation, both for fatal and debilitating diseases. Interestingly, their support of genome editing application concerning the embryo was higher compared with the application for genetically modified food (28.25\%, Figure $1 \mathrm{C})$. This might be caused by a lower acceptance of genetically modified food in this study compared with other studies $(30-57 \%) .^{30,31}$ Nevertheless, similar to other countries, the support for human enhancement at the embryo stage was lower than that for treatment of health-related matters, with only $26.07 \%$ respondents. Moreover, the majority of respondents did not have any view or were neutral regarding the use of genome editing in Indonesia (Figure 1C). 
Table 2 Knowledge and Attitude Toward Genome Editing Application

\begin{tabular}{|l|l|l|l|l|l|}
\hline Question & \multicolumn{1}{|c|}{$\begin{array}{c}\text { Medical Doctors } \\
\text { (Mean } \pm \text { SD) }\end{array}$} & $\begin{array}{c}\text { Medical Students } \\
\text { (Mean } \pm \text { SD) }\end{array}$ & \multicolumn{1}{|c|}{ t } & Effect Size g \\
\hline Q1. Heard GM Food & $2.05 \pm 0.99$ & $1.79 \pm 0.99$ & 4.295 & $\mathbf{0 . 0 0 0}$ & 0.27 \\
\hline Q2. Agree GM Food & $3.17 \pm 0.72$ & $3.20 \pm 0.68$ & 0.810 & 0.418 & 0.04 \\
\hline Q3. Heard GE & $1.5 \pm 0.83$ & $1.61 \pm 0.88$ & 1.985 & $\mathbf{0 . 0 4 7}$ & 0.13 \\
\hline Q4. Somatic Fatal & $3.74 \pm 0.75$ & $3.56 \pm 0.84$ & 3.785 & $\mathbf{0 . 0 0 0}$ & 0.22 \\
\hline Q5. Somatic Debilitating & $3.73 \pm 0.74$ & $3.56 \pm 0.82$ & 3.568 & $\mathbf{0 . 0 0 0}$ & 0.22 \\
\hline Q6. Embryo Fatal & $3.58 \pm 0.87$ & $3.66 \pm 0.82$ & 1.669 & 0.095 & 0.09 \\
\hline Q7. Embryo Debilitating & $3.53 \pm 0.9$ & $3.62 \pm 0.81$ & 1.750 & 0.08 & 0.11 \\
\hline Q8. Embryo Enhancement & $2.83 \pm 0.98$ & $2.96 \pm 0.94$ & 2.144 & $\mathbf{0 . 0 3 2}$ & 0.14 \\
\hline Q9. Application in Indonesia & $3.46 \pm 0.77$ & $3.48 \pm 0.74$ & 0.411 & 0.681 & 0.03 \\
\hline
\end{tabular}

Note: Boldface $p$-values indicate significant differences between groups.

We further explored the respondents' preference regarding enhancing individual characteristics at the embryonic stage. If the technology was safe, the respondents prefer to enhance the intelligence (40.53\%) compared to sport ability/ strength $(28.69 \%)$ and physical appearance (17.52\%). Factors of concern regarding genome editing included the possibility of inheritance (14.19\%), expense (21.93\%), side effects $(22.24 \%)$, violation of privacy $(9.5 \%)$, violation of fate $(15.37 \%)$, violation of religious values $(15.71 \%)$ and others such as misconduct, lack of evidence and less expertise (1.07\%) (Table S2 C1-C5).

\section{Association of Demographic Factors and the Attitude Toward Genome Editing}

To determine the sociodemographic factors affecting the respondents' attitudes on genome editing, Mann-Whitney $U$ and Kruskal-Wallis $H$-test were performed. Our study supported that males were more likely to support genome editing application at somatic cells $(p=0.000)$ and embryo stages, both for health $(p=0.004)$ and non-health $(p=$ $0.001)$ related matter, including its application in Indonesia $(p=0.000)$, similar with other studies (Table 3$)$. This trend might be caused by males tending to follow the logic, while females tend to accept and find a supporting reason (Table S2, C6 and C7).

Age was also a contributing factor affecting Indonesian medical doctors' attitude toward genome editing technology. The older respondents were more likely to support genome editing at somatic cells for treating fatal diseases $(p=0.049)$, and respondents aged 18-30 years and $>50$ years were more likely to support the human enhancement ability ( $p=0.003)$. Moreover, respondents residing outside of the main islands were more likely to support the latter application $(p=0.028)$; however, respondents from the main islands were more likely to support the application of this technology in Indonesia $(p=0.014)$ (Table 3). In the main island, the developments, the facilities and the transfer of knowledge can be performed more easily than in the outer parts of Indonesia.

Religion greatly influenced respondents' attitudes because the respondents with the majority religious affiliation in Indonesia were less permissive concerning applying genome editing application to treat fatal diseases $(p=0.016)$, debilitating diseases $(p=0.000)$ and human enhancement $(p=0.012)$, whether it could or could not be inherited to the next generation (Table 3, S2 C8 and C9). Moreover, they also were more likely to oppose its application in Indonesia $(p=0.001)$ when compared with other religions.

Respondents with higher education levels were more likely to support the application at somatic cells for fatal $(p=0.000)$ and debilitating diseases $(p=0.001)$ but tended to oppose this technology application when used to enhance human ability or performance $(p=0.001)$. This might relate to the ease of access to new information, such as journals, seminars and exchange/internship to developed countries (Table S2 C5 and C6). The exposure to broader society was also associated with respondents being more permissive on implementation in Indonesia $(p=0.014)$; however, this exposure did not significantly 


\begin{tabular}{|c|c|c|c|c|c|c|c|c|c|}
\hline \multirow{2}{*}{ 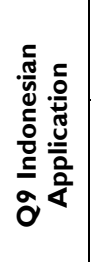 } & 0 & ¿ั & สิ & गे & sọ & 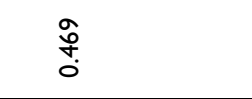 & ্ָণু & ڤ్̂. & $\begin{array}{l}\bar{\sigma} \\
0 \\
0 \\
0\end{array}$ \\
\hline & 变 & 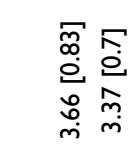 & 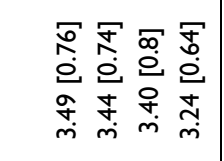 & 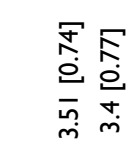 & 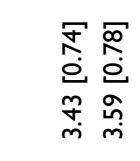 & 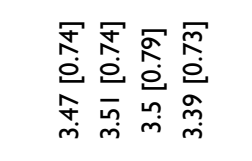 & 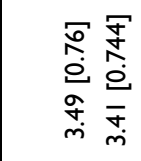 & 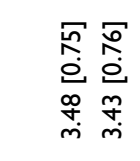 & 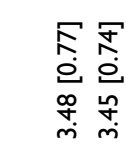 \\
\hline \multirow{2}{*}{ 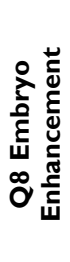 } & a & চ̊̀ & ח̊̊̆ & 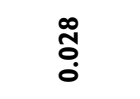 & $\frac{1}{0}$ & $\bar{o}$ & $\overline{0}$ & 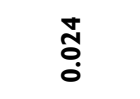 & $\stackrel{\tilde{o}}{0}$ \\
\hline & 蛋 & 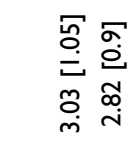 & 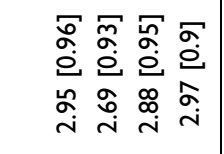 & 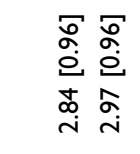 & 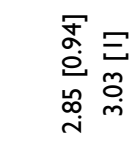 & 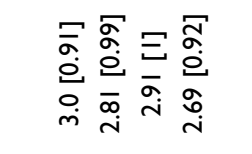 & 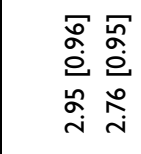 & 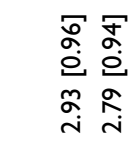 & 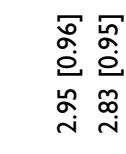 \\
\hline \multirow{2}{*}{ 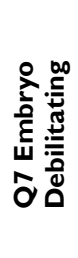 } & 0 & ¿̊̀ & 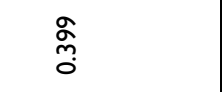 & 葛 & : & $\frac{a}{0}$ & ఫัণ & 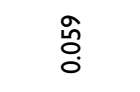 & 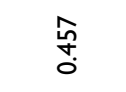 \\
\hline & 䍃 & 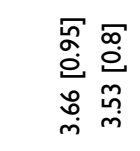 & 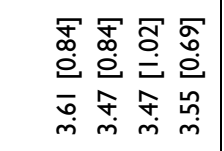 & 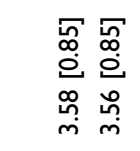 & 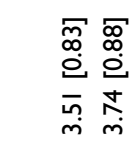 & 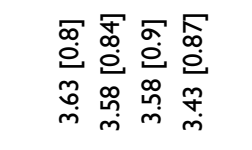 & 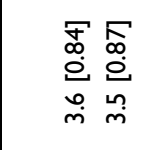 & 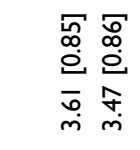 & 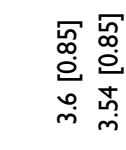 \\
\hline \multirow{2}{*}{ 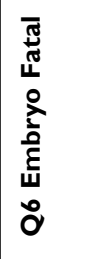 } & a & $\begin{array}{l}\text { ¿े } \\
\text { o }\end{array}$ & $\frac{2}{\alpha}$ & $\stackrel{\infty}{\stackrel{\infty}{N}}$ & ō & $\stackrel{\substack{m \\
0}}{0}$ & $\frac{0}{\mathfrak{n}}$ & 苂 & ڤั \\
\hline & 氞 & 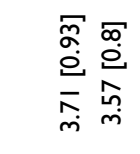 & 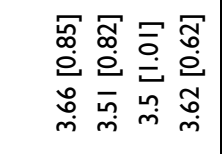 & 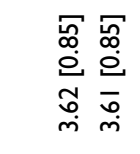 & 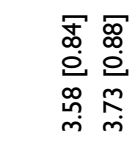 & 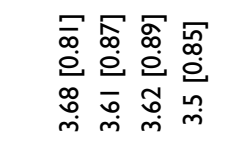 & 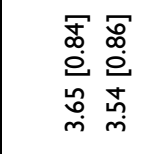 & 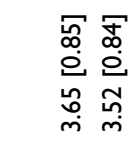 & 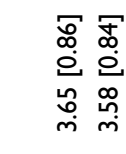 \\
\hline \multirow{2}{*}{ 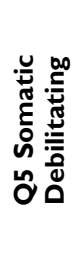 } & a & ¿े & స్ & $\stackrel{m}{\mathfrak{f}}$ & : & ס̊ & $\frac{\text { 궁 }}{0}$ & 品 & ָ̊̊ \\
\hline & 珗号 & 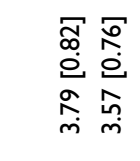 & 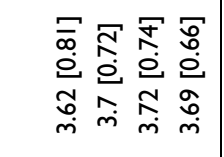 & 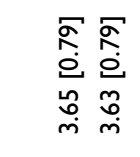 & 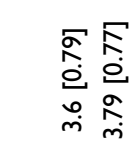 & 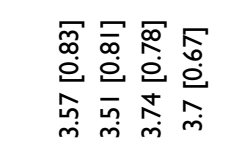 & 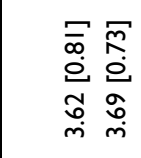 & 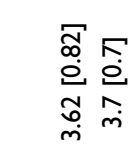 & 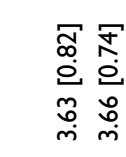 \\
\hline \multirow{2}{*}{ 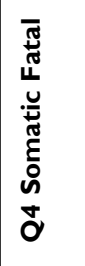 } & $a$ & ¿ั̀ & ờ & $\frac{}{ㅁ}$ & 음 & ¿ั̀ & 苂 & $\overline{0}$ & ल̄o \\
\hline & 秛 & 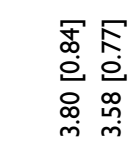 & 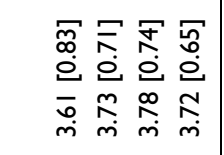 & 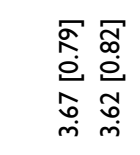 & $\begin{array}{ll}\infty & \infty \\
\stackrel{\infty}{0} & \stackrel{\infty}{0} \\
0 & 0 \\
\dot{m} & \stackrel{0}{m}\end{array}$ & 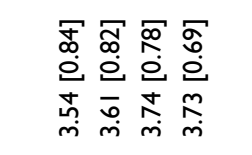 & 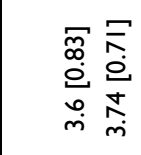 & 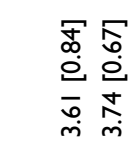 & 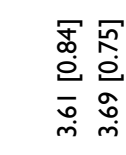 \\
\hline \multirow{2}{*}{ 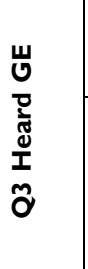 } & $a$ & : & $\frac{\mathfrak{N}}{\mathrm{O}}$ & $\frac{\sigma}{\tilde{m}}$ & $\frac{0}{0}$ & $\overline{0}$ & ষ্் & $\frac{\pi}{0}$ & $\stackrel{\stackrel{\circ}{\stackrel{2}{0}}}{0}$ \\
\hline & 蛋 & 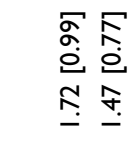 & 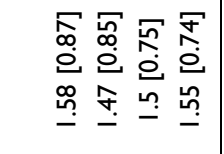 & 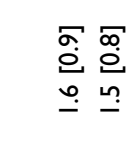 & 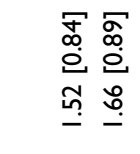 & 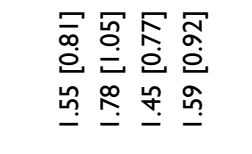 & 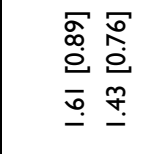 & 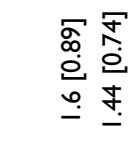 & 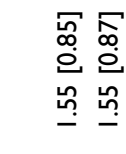 \\
\hline \multicolumn{2}{|r|}{$z$} & $\stackrel{\infty}{m^{\circ}} \hat{R}$ & $\stackrel{\circ}{\circ} \stackrel{2}{-}$ న & 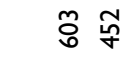 & $\stackrel{m}{n}$ & స్లి సి & $\stackrel{\sigma}{\wedge} \stackrel{m}{m}$ & $\stackrel{\infty}{\stackrel{\infty}{\sim}}$ & 蚣 든 \\
\hline 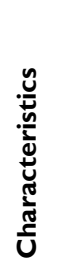 & & 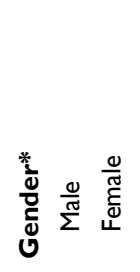 & 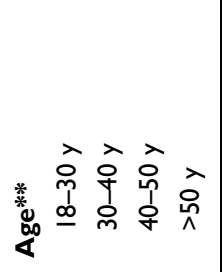 & 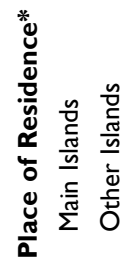 & 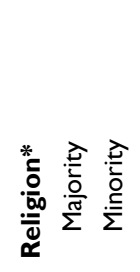 & 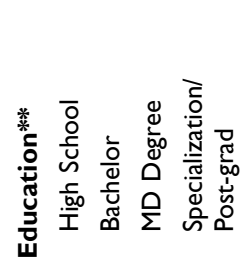 & 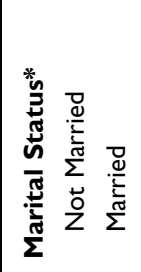 & 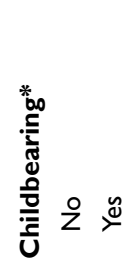 & 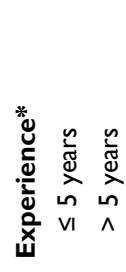 \\
\hline
\end{tabular}




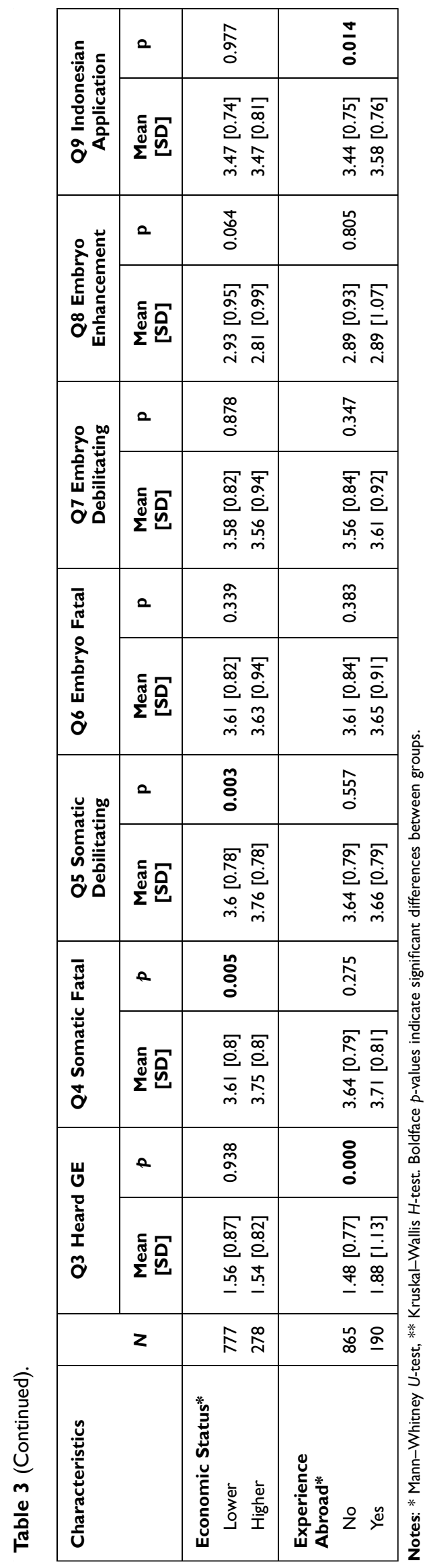

influence their view on genome editing technology in health and non-health-related matter.

Moreover, in line with other studies, respondents with higher self-proclaimed economic status were more likely to support the use of this technology on somatic cells for fatal and debilitating diseases $(p=0.005$ and $p=0.003)$, implying that the changes were unable to be inherited in the next generation (Table S2).

\section{Discussion}

To our knowledge, this constitutes the first study to measure Indonesian medical doctors' and students' attitudes toward genome editing. Our study found that the knowledge of Indonesian medical doctors and medical students on genome editing was lower compared to similar studies in various countries. ${ }^{22,26}$ Moreover, $60.76 \%$ of respondents agreed with the application of genome editing in somatic cells and embryos to improve health conditions. This acceptance reduced to only a quarter when applied to non-health-related aspects. This finding is similar to the public acceptance rate in the United States, where approximately $64 \%$ of the respondents accepted genome editing to cure diseases, while only $33 \%$ respondents accepted its application in enhancing human ability. ${ }^{32}$ Moreover, a study of 1004 Australians demonstrated a similar conclusion. ${ }^{33}$ This finding slightly differs with a study of geneticists in US, in which the majority support the use of genome editing on somatic cells and for research purposes, but not in embryos/germline cells. ${ }^{34}$

As reviewed by Delhove et al, sociodemographic factors influenced the acceptance by the general public toward gene therapy and genome editing. ${ }^{20}$ Our study found that gender, age, economic status, religion, education and place of residence influenced the attitude of the respondents on genome editing technology. Similar to the findings of a study conducted in the US on 1600 adult citizens, ${ }^{32}$ a study on 12,000 persons of the general public (mainly the US, UK and China), ${ }^{26}$ a study on 1004 Australians $^{33}$ and 12,716 persons of the general public of 10 European countries and US citizens, our study found that males were more likely to approve genome editing application, both for disease treatment and human enhancement ability, and its application in Indonesia. This finding differs from that of a study in 13,201 Chinese persons of the general public, with 2165 clinicians, that concluded that females were more likely to accept the application of gene therapy for genetic disease treatments, including genome alterations approach. ${ }^{21}$ 
A relationship between age and the attitude on genome editing has been shown in many studies. Some studies reported that older respondents were less permissive regarding the usage of genome editing, ${ }^{22,33,35}$ especially on non-health-related matters. ${ }^{26}$ However, a study on 10 European countries and US citizens found no significant contribution of age on the application at the somatic cells or the embryos. ${ }^{36}$ In contrast with other studies, here we demonstrated that older respondents were more supportive of genome editing applications to treat fatal diseases at the somatic cells. Additionally, respondents less than 30 years old and more than 50 years old were more likely to permit the usage on non-health-related matters.

Moreover, economic status also might contribute to respondents' acceptance of this technology, especially on its application to the somatic cells. This result was similar to a study from Australia that found the respondents from a country with high economic levels/GDP more likely to accept the implementation of genome editing ${ }^{26}$ and a study from US that showed respondents with higher family income more likely to support the human genome editing technology. ${ }^{32}$ This also might be related with the place of residence, as our study found that respondents who resided at more developed islands were more likely to support the application of genome editing technology in Indonesia, while respondents who resided at less developed islands were more likely to support this technology for enhancing human ability which might bring more benefit. A study in Europe suggested that less support from the lower-income respondents and less developed countries might relate to the lower benefit that they will get from this technology and to trust issues with the regulation and the government. $^{37}$

Another factor that might influence the attitude toward genome editing is religion. As a country with a Muslim majority population, religious value is embedded in many aspects, including the medical field. Our study found that the minority were more likely to agree to its use in health and non-health-related matters, including its application in Indonesia. It was in line with studies in religious individuals who consistently rejected changes to the genome because they conflicted with religious teachings. ${ }^{26,37}$ It might also be related with less trust of the scientific community to guide this technology in a responsible way. ${ }^{32}$ However, a study in the general public, university students and high school teachers from various countries in Asia, Australia, New Zealand, Russia and China found no significant effect of religion on the application of gene therapy that included gene correction. ${ }^{38,39}$

Education was one of the influencing factors on the attitudes of the respondents to this rising technology. Our study found that respondents with higher education had more favorable attitude toward genome editing as treatment for fatal and debilitating diseases on somatic cells, but they were more likely to oppose its application for increasing human ability. Moreover, education did not affect the respondents' attitude toward genome editing application on the embryo, both for fatal and debilitating diseases. A study by McCaughey showed that respondents with tertiary education were more likely to support this technology application as treatment for a fatal or lifethreatening condition, either on somatic cells or embryo stage; in addition, they were also more likely to support their usage to prevents debilitating diseases at the embryonic stage, indicating that the edited gene was inheritable to the next generation. ${ }^{26}$ Similar with our results, studies in Australian, European and US citizens found no significant association between education and prenatal application of this technology. ${ }^{33,36}$ Nevertheless, even though those with experience abroad had increased knowledge regarding genome editing and the CCR5 edited infants, their views of its application did not differ from the respondents who did not have any experience in other countries. Respondents with experience abroad were also more likely to support the implementation of this technology in Indonesia.

Furthermore, even though the cost of CRISPR/Cas is lower than other genome editing technology, Indonesian medical doctors and students still emphasized the high costs that might become a burden on the application, and same reason applies to the reluctance to do genetic testing. ${ }^{40}$ Major side effects or safety of this technology were also a concern, as this technology is still in the development stage, with lack of supportive evidence, and less expertise in the Indonesian medical field. Increasing attention is also given by the Japanese general public, especially after the announcement of twins born with the edited CCR5 gene, mostly regarding the safety and ethical issues. $^{22}$

Unfortunately, even though this technology raised controversial issues in 2018 and received the Nobel Prize in 2020, the majority of Indonesian medical doctors were still unaware of this issue. This implied that more effort was needed to broaden the knowledge of Indonesian medical doctors regarding this new technology approach, so that 
they will be more aware of and prepared for the upcoming treatment technologies. Consultation to the public before its application is necessary before implementation in Indonesia to avoid public negative sentiment and rejection.

We recognized the limitation of our study was the utilization of an online questionnaire; thus, there is a possibility for bias since respondents unfamiliar with the internet or residing in remote areas were unable to access the questionnaire. However, the sociodemographic distribution of our respondents was in line with that of Indonesian citizens. Moreover, without face-to-face interaction, lower engagement with the question might affect the results obtained in this study.

\section{Conclusion}

This study revealed that even though the majority of Indonesian medical doctors and students were unfamiliar with genome editing, they agreed with the use of genome editing to treat fatal and debilitating diseases, but fewer agreed with applying the method to improve non-healthrelated aspects. However, some concerns remain regarding the safety, misuse, ethics, religious values and cost of this treatment in Indonesia. Expanding the horizons and increasing the awareness of Indonesian medical doctors and students regarding new technologies that might affect the future of the medical field and humankind are important.

\section{Acknowledgments}

We would like to thank Dr. Zakiyatul Faizah, MD for valuable comments and suggestions.

\section{Funding}

This study was funded by RKAT Faculty of Medicine Universitas Airlangga as Rector's Decree No. 346/UN3/2020.

\section{Disclosure}

The authors report no conflicts of interest in this work.

\section{References}

1. Lauschke VM, Milani L, Ingelman-Sundberg M. Pharmacogenomic biomarkers for improved drug therapy-recent progress and future developments. Aaps j. 2017;20(1):4. doi:10.1208/s12248-017-0161-x

2. ASGCT. Different approaches. American society gene \& cell therapy. 2020. Accessed 13 March, 2021.

3. d'Arqom A. Nucleic acid therapy for $\beta$-thalassemia. Biologics. 2020;14:95-105. doi:10.2147/BTT.S265767

4. Prado DA, Acosta-Acero M, Maldonado RS. Gene therapy beyond luxturna: a new horizon of the treatment for inherited retinal disease. Curr Opin Ophthalmol. 2020;31(3):147-154. doi:10.1097/ ICU.0000000000000660
5. Stevens D, Claborn MK, Gildon BL, Kessler TL, Walker C. Onasemnogene abeparvovec-xioi: gene therapy for spinal muscular atrophy. Ann Pharmacother. 2020;54(10):1001-1009. doi:10.1177/ 1060028020914274

6. He S. The first human trial of CRISPR-based cell therapy clears safety concerns as new treatment for late-stage lung cancer. Signal Transduct Tar. 2020;5(1):168. doi:10.1038/s41392-020-00283-8

7. Frangoul H, Altshuler D, Cappellini MD, et al. CRISPR-Cas9 gene editing for sickle cell disease and $\beta$-thalassemia. $N$ Eng $J$ Med. 2020;384(3):252-260. doi:10.1056/NEJMoa2031054

8. Bolotin A, Quinquis B, Sorokin A, Ehrlich SD. Clustered regularly interspaced short palindrome repeats (CRISPRs) have spacers of extrachromosomal origin. Microbiology. 2005;151(Pt 8):2551-2561. doi: $10.1099 /$ mic. $0.28048-0$

9. Brouns SJJ, Jore MM, Lundgren M, et al. Small CRISPR RNAs guide antiviral defense in prokaryotes. Science. 2008;321 (5891):960-964. doi:10.1126/science.1159689

10. Ran FA, Hsu PD, Wright J, Agarwala V, Scott DA, Zhang F. Genome engineering using the CRISPR-Cas9 system. Nat Protoc. 2013;8 (11):2281-2308. doi:10.1038/nprot.2013.143

11. Gupta RM, Musunuru K. Expanding the genetic editing tool kit: ZFNs, TALENs, and CRISPR-Cas9. J Clin Invest. 2014;124 (10):4154-4161. doi:10.1172/JCI72992

12. Zhang XH, Tee LY, Wang XG, Huang QS, Yang SH. Off-target effects in CRISPR/Cas9-mediated genome engineering. Mol Ther Nucleic Acids. 2015;4(11):e264. doi:10.1038/mtna.2015.37

13. Liang X, Potter J, Kumar S, Ravinder N, Chesnut JD. Enhanced CRISPR/Cas9-mediated precise genome editing by improved design and delivery of gRNA, Cas9 nuclease, and donor DNA. J Biotechnol. 2017;241:136-146. doi:10.1016/j.jbiotec.2016.11.011

14. Wu Y, Liang D, Wang Y, et al. Correction of a genetic disease in mouse via use of CRISPR-Cas9. Cell Stem Cell. 2013;13 (6):659-662. doi:10.1016/j.stem.2013.10.016

15. Brokowski C, Adli M. CRISPR ethics: moral considerations for applications of a powerful tool. J Mol Biol. 2019;431(1):88-101. doi:10.1016/j.jmb.2018.05.044

16. Cyranoski D. CRISPR-baby scientist fails to satisfy critics. Nature. 2018;564(7734):13-14. doi:10.1038/d41586-018-07573-w

17. Cyranoski D, Ledford H. Genome-edited baby claim provokes international outcry. Nature. 2018;563(7733):607-608. doi:10.1038/ d41586-018-07545-0

18. Cwik B. Moving beyond 'Therapy' and 'Enhancement' in the ethics of gene editing. Camb $Q$ Healthc Ethics. 2019;28(4):695-707. doi:10.1017/S0963180119000641

19. Hirakawa MP, Krishnakumar R, Timlin JA, Carney JP, Butler KS. Gene editing and CRISPR in the clinic: current and future perspectives. Biosci Rep. 2020;40(4):BSR20200127.

20. Delhove J, Osenk I, Prichard I, Donnelley M. Public acceptability of gene therapy and gene editing for human use: a systematic Review. Hum Gene Ther. 2020;31(1-2):20-46. doi:10.1089/hum.2019.197

21. Wang J-H, Wang R, Lee JH, et al. Public attitudes toward gene therapy in China. Mol Ther Methods Clin Dev. 2017;6:40-42. doi:10.1016/j.omtm.2017.05.008

22. Watanabe D, Saito Y, Tsuda M, Ohsawa R. Increased awareness and decreased acceptance of genome-editing technology: the impact of the Chinese twin babies. PLoS One. 2020;15(9):e238128. doi:10.1371/journal.pone. 0238128

23. Indonesian Medical Council. The National Standards Competencies of Indonesian Medical Doctors; 2012. Available from: http://www. kki.go.id/assets/data/arsip/SKDI_Perkonsil,_11_maret_13.pdf. Accessed March 13, 2021.

24. Webster PC. Indonesia: islam and health. CMAJ. 2013;185(2):E101E102. doi:10.1503/cmaj.109-4364

25. Fritz RL, Vandermause R. Data collection via in-depth email interviewing: lessons from the field. Qual Health Res. 2018;28 (10):1640-1649. doi:10.1177/1049732316689067 
26. McCaughey T, Sanfilippo PG, Gooden GE, et al. A global social media survey of attitudes to human genome editing. Cell Stem Cell. 2016;18(5):569-572. doi:10.1016/j.stem.2016.04.011

27. Brydges CR, Sands LP. Effect size guidelines, sample size calculations, and statistical power in gerontology. Innov Aging. 2019;3(4) igz036-igz036. doi:10.1093/geroni/igz036

28. Hedges LV, Orlando IO. Statistical Methods for Meta-Analysis. San Diego: Academic Press; 1985.

29. Health SHTHCSoP. The Public and Genetic Editing, Testing, and Therapy. Boston: Harvard T.H. Chan School of Public Health; 2016.

30. Shew AM, Nalley LL, Snell HA, Nayga RM, Dixon BL. CRISPR versus GMOs: public acceptance and valuation. Glob Food Secur. 2018;19:71-80. doi:10.1016/j.gfs.2018.10.005

31. Huang J, Qiu H, Bai J, Pray C. Awareness, acceptance of and willingness to buy genetically modified foods in Urban China. Appetite. 2006;46(2):144-151. doi:10.1016/j.appet.2005.11.005

32. Scheufele DA, Xenos MA, Howell EL, Rose KM, Brossard D, Hardy BW. U.S. attitudes on human genome editing. Science. 2017;357(6351):553-554. doi:10.1126/science.aan3708

33. Critchley C, Nicol D, Bruce G, Walshe J, Treleaven T, Tuch B. Predicting public attitudes toward gene editing of germlines: the impact of moral and hereditary concern in human and animal applications. Front Genet. 2019;9:704. doi:10.3389/fgene.2018.00704

34. Armsby AJ, Bombard Y, Garrison NA, Halpern-Felsher BL, Ormond KE. Attitudes of members of genetics professional societies toward human gene editing. CRISPR J. 2019;2(5):331-339. doi: $10.1089 /$ crispr. 2019.0020
35. Weisberg SM, Badgio D, Chatterjee A. A CRISPR new world: attitudes in the public toward innovations in human genetic modification. Front Public Health. 2017;5:117. doi:10.3389/ fpubh.2017.00117

36. Gaskell G, Bard I, Allansdottir A, et al. Public views on gene editing and its uses. Nat Biotechnol. 2017;35(11):1021-1023. doi:10.1038/ nbt. 3958

37. Hudson J, Orviska M. European attitudes to gene therapy and pharmacogenetics. Drug Discov Today. 2011;16(19):843-847. doi:10.1016/j.drudis.2011.06.008

38. Macer DR, Akiyama S, Alora AT, et al. International perceptions and approval of gene therapy. Hum Gene Ther. 1995;6(6):791-803. doi:10.1089/hum.1995.6.6-791

39. Xiang L, Xiao L, Gou Z, et al. Survey of attitudes and ethical concerns related to gene therapy among medical students and postgraduates in China. Hum Gene Ther. 2015;26(12):841-849. doi:10.1089/hum.2015.113

40. Blendon RJ, Gorski MT, Benson JM. The public and the gene-editing revolution. $N$ Eng $J$ Med. 2016;374(15):1406-1411. doi:10.1056/ NEJMp1602010
Journal of Multidisciplinary Healthcare

\section{Publish your work in this journal}

The Journal of Multidisciplinary Healthcare is an international, peerreviewed open-access journal that aims to represent and publish research in healthcare areas delivered by practitioners of different disciplines. This includes studies and reviews conducted by multidisciplinary teams as well as research which evaluates the results or conduct of such teams or healthcare processes in general. The journal

\section{Dovepress}

covers a very wide range of areas and welcomes submissions from practitioners at all levels, from all over the world. The manuscript management system is completely online and includes a very quick and fair peer-review system. Visit http://www.dovepress.com/testimonials. php to read real quotes from published authors. 